\title{
Status and application of informatization on the construction management
}

\author{
Lin Fang \\ Chengdu Technological University \\ Chengdu,Sichuan,China
}

\author{
$\mathrm{Kai} \mathrm{Hu}$ \\ Chengdu Software Industry Development Center \\ Chengdu,Sichuan,China
}

\begin{abstract}
Network information technology is the product of the combination of communication and computer technology. The computer network is to interconnect the world dispersed and independent computers in accordance with the network protocol. With the rapid development of information technology at home and abroad, the developed countries or parts of the developing countries are strengthening their national information infrastructure. Several of gold projects in information technology as the representative is gradually go deeper, forming an unprecedented development in the entire information network technology. With the globalization of the construction market and intensifying of the competition, construction management requires the higher information technology, which is relatively backward in China's construction industry. So it has important practical significance to clearly recognize the entire network computing model and technology developments, and properly apply to the construction project management.
\end{abstract}

Keywords- informatization. Construction management. personnel development

\section{INTRODUCTION}

Information technology of the building enterprises has increased annually. With increasingly fierce competition, many construction companies began turning to information technology, and some of the larger or higher level of companies first established a local area network to achieve resource sharing data across the enterprise, at the same time, the project management software has become one concern.

Domestic project management software is still in an immature state. There is a gap by compared with some famous foreign software. Foreign software are often not very suitable for domestic enterprises, because the domestic and foreign enterprises have different organizational structures, then the scope of software application will also be different. The so-called localization software is just translated from English into Chinese, so the effective maintenance must be difficult. And most of this foreign software is very expensive; as a result, the general corporates can't bear it.

\section{THE STATUS OF CONSTRUCTION MANAGEMENT INFORMATIZATION IN CHINA}

\section{A. Less deep understanding in construction project management informatization}

Many construction companies have less understanding and attention of the informatization of the management, so that they did not put too much manpower and material resources in the actual development and applications. Most of the construction company's leadership and staff mostly stay in the lip, but less action in practice. They generally believe that the so-called information technology is to equip with several computers for internet, or is set up the company's website to publicize the performance of enterprises. The second is to replace the manual labor with computers to achieve the office informatization. This misconception causes a serious obstacle in informationizing the project management technology.

\section{B. Construction Project Management Software is not yet mature}

At present, China's construction management application software is divided into two kinds: one is the modified software from abroad; the other is our self-developed software. Both software are not mature enough. The imported software is not suitable for China's national conditions for their narrow application. As China's cultural and social environment and institutional regulations are different from the abroad, a lot of imported software is required to transform. But, in fact, because the effect of the transformation cannot be accurately grasped, many software used by low-level foreign workers can only be used by the higher level staffs in our country. And domestic staffs are not in the same level in applying the software, with many people formally controlling the software, but not practically applying in management. In addition, with the rapid development of information technology, the introduction of the software is often not keep up with software updates extent. Also, the effectiveness of many software developed by China are very low on information management, which are unable to adapt to the rapidly changing environment within the enterprises.

\section{Integration of the Information System}

The workflow of the construction industry is very complicate, which adopts a lot of national or local industry standards in the implementation of the project. These standards are very complicate, with the amount of data being quite large, and the application being quite flexible. In addition, there are schedule progress, fund management, quality assessment and other aspects being involved in the construction, which are the important construction management components. Therefore, when developing the information system, it is necessary to take the above 
standards into account to break through the limitations of a single application.

\section{THE NECESSITY OF THE CONSTRUCTION MANAGEMENT INFORMATIZATION}

Construction management is a complex process, including construction quality management, construction schedule management, technology management, and many other aspects of construction. It is no doubt that it will be a long and complex task for construction management to achieve information technology. But the realization of construction management of information technology will greatly enhance the management level of the enterprises.

\section{A. Information technology will help companies make strategic planning}

The corporates are planning and implementing the budget management, fund management, production monitoring, project management and other aspects of information technology step by step with high standards, so that we can focus on the company's core business to build up the thematic databases, functional model, data model and information architecture model, and work out the corporate strategic data plan.

\section{B. The government administrative departments should actively guide the construction management information technology}

First, from view of the policy development, it needs to strengthen the government's leading role in the development of practical policy measures to provide protection for construction of information technology. Take the United States as an example, in 1993; the U.S. implemented the "National Information Infrastructure" programed of action to provide a high-speed network platform for the enterprise information that enables enterprise information technology entering a rapid development stage. In this process, the U.S. government recognized the market value and huge potential of the business with Internet, and established the American Business Alliance in 1995 in Silicon Valley to help government promote the e-commerce planning work.

\section{Accelerate the development of the domestic software and information systems and enhance the adaptability of the system}

Construction industry, especially railways, highway construction and others are easily influenced by environmental factors. For example, the public works, housing construction and others are vulnerable to be limited by the weather changes, geological conditions, construction time constraints, noise and environmental requirements, which will affect the progress of the project and the capital budget. While the foreign software is often difficult to adapt to these changes of parameters, therefore, we should be more responsive to speed up the development and application of the domestic construction management software and related information system to adapt to the China's construction industry.

\section{Establish and improve the construction management}

Information technology is not only a technological change, but also a profound management change. To accomplish this transformation, we must abandon the habit of thinking, ways of working and even lifestyle. Therefore, in the information technology strategic planning, it is not only to establish the highest political level in the company's organization with leadership personally working, all staffs working, overall planning and the system advancing, but also require the consistent actions and unified ideology.

\section{CONSTRUCTION BUSINESS PROCESSES, ORGANIZATION AND PERSONNEL DEVELOPMENT}

\section{A. Building Business Processes and Organization}

Building business processes and organizational transformation hysteresis, enterprise management and process reengineering do not match. Business process reengineering is the enterprise management to the flat direction for the development of a fundamental rethinking and radical redesign sex is a traditional management system of the enterprise property right system, beating until fundamental changes in style. As we all know, construction of information management process reengineering process is a process that requires the entire industry management mode fundamental changes, not just local, detail improvements, optimizations. Unused part of building enterprise management information system for management, so in the course of construction project management business process also maintains the original form, the organization is still stuck in the past organizational model.

\section{B. Necessary technical team is lack in the construction management}

Men are an important part in the engineering information management. The success of the information technology project management ultimately depends on the men, who construct, apply and maintain the information systems, depends on the quality of men, and depends on whether owning a high level of information team. In China, the quality of construction management personnel is uneven. On the whole, it is still in a low level, and lacking of a high-level technical team to lead the project management information.

\section{GOVERNMENT ADMINISTRATIVE DEPARTMENTS AND CONSTRUCTION COMPANIES}

Currently, some domestic construction companies have set up their own business website, but most of them just put the website as an information release window to promote corporate's image, rather than to release diverse information for the specific ones. What's worse, they did not take commerce as a low-cost, high-efficiency trade way. So that it requires the effective policies from the government administrative departments to correctly guide, at the same time, the government can also initiate administrative departments to establish and improve the relevant construction organizations of the information technology, and to develop e-commerce building industry norms, to 
absorb the construction business, general contractors and material suppliers, to guide and supervise them with effective policies. Through the optimization and integration, under the premise of the specification, learn from each other and promote the enterprises' development, including a series of e-commerce systems, such as the project bidding, project development and procurement of raw materials, so as to reduce the costs and to improve efficiency.

\section{CONSTRUCTION APPLICATION MANAGEMENT AND COMPUTER INFORMATION TECHNOLOGY MANAGEMENT}

Driving our 21st century business with information technology is a major strategic initiative in China. Informatization is a socio-economic process by depending on the computer and the Internet to transfer the enterprise economy into an information economy, which includes the automatic control of the information collection, information storage automation, utilization automation of the information exchange network, information retrieval instrumentalization, information management systematization, information utilization identification, information management project systematization and so on. Information technology is that the companies collect store, process and suport decisions by using the scientific methods for enterprise management information. Computer technology is the primary and indispensable information means. Obviously, the former includes the latter. To avoid confusing their concepts, we must have a correct understanding of the both.

\section{A. The range of the Building Enterprise Information applications is relatively narrow}

The current application of the construction industry informatization is relatively narrow, which mainly focuses on the early stage of project construction, bidding, and construction cost estimation, project design, while less in the progress, quality and safety control of the cost during the process. Firstly, the project construction management is still mainly rely on managers' experience and capabilities, which is not very scientific in accordance with the current demands, as a result, it cannot keep up with the current information management system. Secondly, there are obvious limitations of the computer applications in the construction industry, which mainly applies the standalone software to carry out the stand-alone operation. It is only benefit from the computer's speed, but there is no network information sharing and automatic transmission.

\section{B. The control progress of the Network schedule Management Software}

According to the construction schedule, timely adjust the resource and optimize the time to adapt to the changing circumstances in the construction site. Such software is relatively mature at present. In quality control, the quality management is an important part in the construction management, which is with large information, strong synthesis and difficult technology. Compared with the manual operation, the application of the quality management software has prominent advantages: the processing time being short and the reliability of the results being high.
Quality management software system can be used in all stages of the construction process quality control and evaluation, quality management personnel so as to provide a reliable material guarantee for the managers to implement the dynamic control of quality.

\section{IMPLEMENTATION PROPOSAL OF INFORMATION TECHNOLOGY PROJECT}

\section{A. Building a multi-level management platform}

Many foreign stokeholds such as owners, supervisor, design, local government and the higher administrative authorities, and many aspects of management, such as contract management, on-site construction management, financial management, budget estimation management, materials and equipment management are involved in the implementation of the construction projects. Therefore, the project informatization should fully consider the requirements of various participants and build up a multilevel software system and network information platform which have covered the on-site construction management, project RMON, multi-project collaboration, enterprise knowledge and information management, can automatically generate the data of different subjects to achieve a variety of information resources.

\section{B. Creating a data-centric workflow}

Project management is the data flow and delivery among the various participants.under the traditional management mode, the information is carried out slowly and repeatly in writing, telephone, fax, etc. The obtaining of one aspect of information must be cooperating with relevant departments, which largely reduces the timeliness, effectiveness and economy of information transmission. In order to avoid duplication and overlap, it is necessary to speed up information transmission and improve the quality of information transmission. Project informatization system must be data-centric; the work responsibilities and content of the project participants must be on the basis of the data management, so as to achieve "one input, multiple applications", which means that everybody in the project shall only complete their own work, then the system will achieve business automatic flow.

\section{CONCLUSIONS}

In the development of network information technology applications, there is a certain gap between the construction management and other industries, likewise, the application of network technology between the developed countries and the developing countries in this industry. How to eliminate information gaps should be a very meaningful research in the current construction project management. Therefore, it should not just focus on one aspect, but a comprehensive one. Comprehensively open and apply the network information technology in the construction management. 


\section{References}

[1] Zhang Jianping. Talking about IT in Construction Management [J]. Technology and Innovation Management ,2005,04:57-59.

[2] Shang Chunjing, Liu Changbin. Construction Engineering Management Information [J]. Construction Economics ,2004,08:26 29.

[3] Mengqing Jun. Architectural Engineering Management Engineering Change Management [J]. Installation ,2005,02:14 -16.

[4] Wang Hongtao, Wang Li. Concurrent Engineering in Construction Engineering Management [J]. Economic Forum ,2006,18:73-75.
[5] Zhang Haifeng. Discussion of Construction Management Information Status [J]. China Construction Information ,2007,10:26 -29.

[6] Chen Chunmei. Information Technology in Construction Project Management study [J]. Sichuan Building Science ,2007,05:229 -232.

[7] Ren Guoqiang, Zhang Hongyan. Game Theory in Construction Project Management Application Research [J]. Tianjin University of Technology ,2008,01:86-88.

[8] Du Pengfei. Preliminary Construction Management Information [J]. Chinese high-tech enterprises ,2009,08:127 -128. 